\title{
Individual Income Tax Reform and Wealth Redistribution in China
}

\author{
Yawei Zhang ${ }^{1}$ \\ ${ }^{1}$ Ph.D. Candidate, School of Civil, Commercial \& Economic Law, China University of Political Science and \\ Law, Beijing, China \\ Correspondence: Yawei Zhang, Ph.D. Candidate, School of Civil, Commercial \& Economic Law, China \\ University of Political Science and Law, Beijing, China. E-mail: zhangyawei_cupl@163.com
}

\author{
Received: November 4, 2014 Accepted: November 12, 2014 Online Published: November 15, 2014 \\ doi:10.5539/jpl.v7n4p112 URL: http://dx.doi.org/10.5539/jpl.v7n4p112
}

\begin{abstract}
The immature of the contemporary Chinese individual income tax (IIT) system induce the unjustified wealth redistribution to some extent. This article would not only analysis the relationships between the individual income tax and the wealth redistribution in China, but also positions the defects in the current Chinese IIT system. Apart from that, after referencing the foreign IIT mechanisms and analysis their advanced ideas, the author combines foreign experience with the Chinese native conditions in order to advise for introducing both the classification-consolidated IIT leaving system and the rational deduction system to the current Chinese IIT legal system. The scope of the Chinese IIT is suggested to be wider and the electronic tax leaving and information collection systems would also be the developmental direction of the future Chinese IIT system. All these reforms suggested are beneficial to the fairness of the current Chinese IIT legal system and they would enable the Chinese IIT legal system better achieving its wealth redistribution function.
\end{abstract}

Keywords: Chinese individual income tax, reform, wealth redistribution

\section{Introduction}

China is going through a period of rapid economic development and the income of both urban and rural residents has gone up sharply. However, in the meanwhile, the marked disparity of income distribution and the inequalities in wealth are receiving more and more attention. In February, 2013, the Chines state council issued the "Notice of the state council on approving and forwarding opinions of NDRC MOF and MOHRSS on deepen the reform of the system for income distribution", which gives an official acknowledgment of facing the outstanding problems including the disparity of income distribution, the disorder of the income distribution system, the invisible income and the illegal income in the contemporary domestic mechanism.

\section{The relationship between the Individual Income Tax and the Wealth Redistribution}

The problems of the current domestic wealth distribution concentrated on the process of primary distribution and the redistribution. Generally speaking, the ultimate target of income distribution is to achieve both the equity and the efficiency in wealth distribution. However, due to the development pressure and the defects in China's immature market economy, the primary distribution, which takes efficiency as foremost, can hardly make contribution to the goal of narrowing the gap in wealth distribution. Therefore, it is more realistic to utilize and relay on the redistribution mechanism to adjust the wealth distribution as well as realizing the equity on it.

Among all the tools that could be utilized in wealth redistribution, taxation always be seemed as the most efficient one, which could largely promote the fairly distribution of personal income. In the taxation system, only the property tax and the income tax are the most efficient taxation tools in adjusting the personal income and narrowing the revenue gap. In current Chinese tax system, there are three main categories of tax, which are the circulation tax system, the income tax system and the property tax system. All the categories of tax in the circulation tax system except the consumption tax are levied in accordance with proportion, which has no progressive feature and thus has no functions in narrowing the gap of personal income. What's more, China still has not established effective property taxation mechanisms such as housing tax and death duties, which could contribute to the wealth redistribution by levying the existed assets. Therefore, the income tax mechanism would be the most effective taxation tool for the adjustment of wealth redistribution. More specifically, among all the categories of income tax, the individual income tax is the most suitable instrument for adjusting personal wealth redistribution due to its progressive feature and the direct influence on individuals. Thus, the Chinese IIT system 
could play vital roles in regulating the wealth redistribution and realizing the equity in income distribution.

However, there are a bunch of defects and drawbacks in the contemporary Chinese IIT system, which would not only hinder its target in achieving the equity in the wealth redistribution, but also widen the income gap and even finally in breach of the fairness redistribution doctrine. For instance, in reality, the existing IIT system actually acquire more tax revenue from the salary of working class rather than the capital income of the wealthy class, which actually cause the regressive taxation to some extent and in breach of its original designed functions.

Thus, in order to effectively utilize the IIT system to improve the equity of the wealth redistribution, the current IIT system needs to be reformed and renovated in the aspects of fairness and efficiency in the wealth redistribution.

The following article would firstly analysis the existing defects in the current IIT system combing with its wealth redistribution function. Then, the article would make a comparative study to show several renowned foreign IIT system and the implementation of their mechanisms. The third part would try to give suggestions to the current PRC IIT system reformation for the purpose of improving its effectiveness in wealth redistribution.

\section{The Defects in the Current PRC IIT System}

\subsection{Defects of the Current Schedular IIT System}

The current PRC IIT system can be categorized as schedular income tax system, which levy the different types of individual income by using different tax rates. The IIT system divides the individual income into 11 categories, which implement different tax rates, deductions and taxation methods respectively. The benefits of the schedular system is that it requires a relatively simple design of the tax system and could made the levy and calculate of taxation more straight-forward.

However, there are also some apparent defects in this system. For one thing, the current schedular IIT system generates horizontal unfairness in its tax levy. Firstly, under the schedular structure, similar categories of income could bear very different tax burden, which in breach of the horizontal equity principal of taxation. For instance, according to the current IIT system, if two citizens acquire the same 15000 yuan income by wages or by production or business operation conducted by self-employed industrial respectively, the tax burden for that amount of wages are 1870yuan while the tax payer for the production or business operation conducted by self-employed industrial only need to bear 750yuan of IIT, even if their burden and characteristics of work are relatively similar. Secondly, according to the IIT law, different types of individual income might bear different degrees of IIT. In practice, those who earn income from various channels always bear less IIT burden than those citizens who acquire their salary from single channel, even if they obtain the same amount of total income. That's because those people who enjoy various types of income could avoids or evades its taxes by changing the project and category of their taxable income.

For another, the current schedular IIT system also generates vertical unfairness in its tax collection. Compared with the working class, the wealthy persons always enjoy more channels of income, which means it is relatively easier for them to verify and separate their incomes in order to avoid or evades their IIT, and even bear lower tax burden than the poorer residents. This defect would seriously influence the progressive wealth redistribution function of the contemporary individual income tax system.

\subsection{Defects in the Deduction System}

The PRC IIT system applies the quota deduction model, which gives fixed deduction to certain taxable items. However, although this system design makes no discrimination in procedure, it actually creates inequality since it has no consider of the individual differences and the taxable capacity.

More specifically, the PRC IIT system has not considered the actual individual basic living expenses in its deduction mechanism. The current PRC tax law has a fixed living expense deduction of 3500yuan, which not only ignores the actual taxable ability of different individual tax payers, but to a large extent also lowers the redistribution function of the IIT and breaching the horizontal equity principle of taxation. For instance, if there are two tax payers who acquire the same amount of salary, however, one of them need to bear the expense of supporting the elderly, educating the children and pay for their medical care while his counterpart only need to bear his own living expense. According to the current IIT law, these two tax payers would enjoy the same amount of deduction. It is true that this mechanism could realize the procedure equity to some extent, but it indeed create substantive injustice, and it could not achieve the equity of wealth redistribution. Apart from that, the deduction has no connection with the CPI and the inflation index, which actually reduce the real deduction amount in the situation of inflation. And it would also sharply improve the real tax burden of lower income group since the inflation actually lower the amount of fixed deduction and widen the real tax base. 


\subsection{Defects in the Tax Levy}

Firstly, the contemporary local PRC tax departments do not have an inter-related tax information center, which create the phenomenon that the levy department could not get the effective integrated information of the individual taxable revenue in the aspect of regions and time periods respectively. And that would lead to the avoids or evades of taxes. According to the investigation of Xiaolu Wang, the domestic invisible income accounts for nearly 9.3 trillion yuan, which became as a major reason of the wider gap between citizens' income as well as creating the losses of the IIT revenue.

What's more, the incomplete information and the lack of levy capacity would also further widen the income differences. In China, most middle and low income stratum rely on the wage and salary as their main income source, which could hardly carry out the evading of tax due to its transparent feature and the withholding tax mechanism. On contrary, the incomes of wealthy class always come from capital investment and the conveyance of property, which always originated from various sources with convert feature. What's more, the lack of information and capacity in the tax levy would make it easier for the wealthy people to avoid their due IIT and might also reversely make the poor to donate more IIT than their wealthy counterparts, which actually in breach of the equity in wealth redistribution and the ability theory of taxation.

\subsection{The Unreasonable IIT Allocation among the Wealthy and the Poor}

According to the index of MOF, the working class almost donates half of the IIT in recent years, which largely in contrary with the wealth redistribution adjusting purpose of the IIT.

Nowadays, the wealthy class actually acquires a large proportion of their income by using capital instruments. However, in PRC IIT items, the only clearly defined capital taxable items are the income from the lease or transfer of property. Many other more commonly implemented capital incomes such as income from fund, trust and other new financial products still do not bear the IIT burden even if they produce a large amount of income for the wealthy class. And that also provides the rich strata with a lawful tax avoidance method and consequently amplified the income disparity in reality.

\subsection{The Defects in the Tax Rate and Progressive System}

In the current PRC IIT system, with respect to income from wages and salaries, the taxable income in excess of the specified amounts shall apply with a progressive tax rates ranging from 3 percent to 45 percent. With respect to income from remuneration for personal services, there is a fixed rate of $20 \%$. With respect to income of self-employed industrial and commercial households from production or business operation and income of enterprises or institutions from contracted or leased operation, the progressive tax in excess of the specified amounts shall apply, with the tax rates ranging from 5 percent to 35 percent .With respect to income from royalties, interest, dividends, bonuses, lease of property, transfer of property, incidental income or income from other sources, a flat rate, which is 20 percent, shall apply.

This tax rate and progressive model would cause the following problems in wealth redistribution: firstly, in this mechanism, the tax burden of working income is apparently higher than unearned income. The IIT system levy only $20 \%$ flat tax on interest, dividends, and property dependent incomes while put a maximal $45 \%$ progressive rates on salary and wages, which made it very likely for the working class and self-employed households to bear higher tax burden than those rich people who earn from unearned incomes such as interest, dividends and property dependent incomes. And that indeed in breach of the equity redistribution idea of the IIT mechanism and create retro-regulation to some extent.

Secondly, the 7-tier progressive tax mechanism for wages and salaries also cause certain problems. On the one hand, the model is too complex and create obstacle in calculation. On the other hand, according to the statistical information, most tax payers apply to the tax rates from $3 \%$ to $25 \%$, and the tax rates beyond $30 \%$ are rarely applied, which reveal the unscientific of the legislation. What's more, the exorbitant maximal IIT rate would also lower China's international competitiveness of tax.

\subsection{Defects of the Scale of the Current IIT}

Generally speaking, the IIT mechanism has a comparatively strong progression, and it could effectively adjust the income gap among tax payers.

However, the effectiveness of the IIT system in adjusting the income gap largely associated with the size of the taxation. Only if the collection scales of the IIT account for a reasonable proportion in the whole tax system is it possible for the IIT to use its progressive characteristic to minor the income gap and further promote the equity of wealth redistribution. 
According to the investigation of foreign tax system, most of the developed countries use IIT as their major source of tax revenue. For example, when we look at the average ration of IIT revenue among the whole tax revenue of the developed countries from 1986-1992, we would find the following figures: The US (46\%), UK(31\%), Australia (56\%), Japan (39\%) and German (15\%). And the average percentage of IIT revenue among GDP of all OECD countries from 1996-2000 is $10.9 \%$.

When it comes to the PRC IIT system, the IIT revenue only accounts for $5.8 \%$ of the total tax revenue in 2012, and even lower in former years. And that largely hindered the IIT from effectively adjusting and narrowing the income divide.

\section{Foreign Experience}

In order to perfect the current Chinese IIT system, it is inevitable that we need to make comparison between foreign countries and borrow their successful experience, but it should be paid enough attention that the most critical point in legal transplantation is not the well operation of foreign mechanism in their own countries, but the acceptability of this mechanism in the native system. There are many well operated taxation measures in foreign countries which are especially designed for restoring the indigenous defects in their systems. However, since those defects do not exist in other jurisdictions, these effective mechanisms would be rootless and invalid in the Chinese system. So it is of great importance for this research to look for mechanisms that are suitable for the PRC system. The following aspects of foreign experience could be a relative good reference for the contemporary Chinese IIT law reformation.

\subsection{Tax System}

The United States and UK all adopted the global IIT system, which has the progressive feature and could well achieve the redistribution function of the IIT as well as maintaining the neuter of taxation. The Russia and Korea both adopted the classified consolidated model, which globally levy the IIT of most taxable incomes while separately collect a small amount of IIT by using the schedular system. In this situation, it is more convenient for the country to use IIT as an instrument for macroeconomic control.

\subsection{The Indexation Adjustment of the Deduction and Tax Rate}

The indexation of IIT represents the adjusting of deduction and tax rate by referencing the CPI and inflation index, which could avoid the actual fluctuation on deduction and tax rate induced by the inflation or deflation. The USA, US and Korea all combine this mechanism into their IIT system in order to better avoiding the fluctuation of the real tax burden in the inflation or deflation situation.

\subsection{Advanced Levy System}

Some developed countries use the following method to help the collection of their individual income taxation. For instance, the USA and Canada implement the tax identification number system, which not only combines the ID card with the tax information, but also connect the ID number with the individual bank account in order to better share the individual taxation information with other organs.

\subsection{Broader Tax Bases}

In many developed countries, the IIT accounts for the largest part of the whole taxation system, which provides an outstanding function for wealth redistribution. For example, the following figure represent the average percentage of IIT in the whole tax system in different countries from 1986-1992: USA(46\%), Japan(39\%), German $(15 \%)$ and the average figure for Asia countries is $12.7 \%$. The broad tax base and the massive tax quantity would give the IIT a better ability to adjust the wealth redistribution by using its progressive feature.

\section{The Reform of the Current IIT System}

Due to the aforementioned defects, the current PRC IIT system need to be reformed in order to better achieve its wealth redistribution function, the following article would provide suggestions for the possible amendments for the current IIT system.

\subsection{Implementation of the Classified Consolidated IIT System}

\subsubsection{Schedular IIT System}

The schedular IIT system would divide the individual income into various categories and levy the different categories of tax by using different tax bases and tax rates. Its main theoretical basis is that different categories of individual income shall be taxed separately.

There are two main advantages of the schedular system, firstly, it could levy the tax by withholding at source, which could minimize the cost of collection. Apart from that, the schedular system could achieve certain policy 
goals by using discriminatory taxation structure on different sources and characters of income. For instance, it could put higher tax burden on capital gains rather than on working salaries in order to maintain the horizontal justice.

However, the schedular system still have certain drawbacks, since the schedular system provide tax rates based on the category and nature of income, it could provide those who acquires various types of income a great opportunity to avoid or evade their tax by transferring the category of their income. And that would finally widen the income gap since those wealthy people who have higher income and more income sources could conversely submit less IIT than the working class who acquire fixed salaries or wages, which in breach of the ability-to-pay and vertical justice principals of taxation.

\subsubsection{The Global IIT Tax}

The global income tax system would levy the taxable individual income of certain period globally without regard for its categories and sources. The outstanding characteristic of this system is that it put different types of income into a general tax bracket and applies to the consolidated tax rate.

The global system is originated from German and there are three main benefits of this system. Firstly, compared with schedular system, the global system has a wider tax base, which could better adapt to the tax payers' ability-to-pay principal. Meanwhile, the global levy system would be more convenient in adopting the deduction based on the burden of the individuals and their families. Apart from that, the tax payers could not avoid or evade their IIT by transforming the category of their income in the global system. Lastly, the progressive feature of the system could well achieve the redistribution function of the IIT as well as maintaining the neuter of taxation.

Nevertheless, the defects of the global system mainly concentrated on the levy procedure. The implementation of the global IIT system and the accurate calculation of global income would need the corporation of a sound declaration and information system, which could hardly be perfectly built. Therefore, nearly no country applies the pure global system in the contemporary world.

\subsubsection{The Classified Consolidated IIT System}

The classified consolidated tax system combines the merits of global and schedular system, which not only levy the classified tax, but also globally tax the whole revenue. More specifically, this model could be divided into two categories, the first model levy the income tax by items initially while progressively tax those global yearly income which exceeds a certain criteria. However, the levied schedular tax before could be deducted finally. The second model globally levies tax payers on some specific items while tax other projects by withholding at source.

The merits of this system is that it could not only accept the wide tax base and progressive feature, which promote the fairness of taxation, but also achieving differential taxation to some extent and maintain the ability of political adjustment. However, this system also needs a relatively full-fledged levy system as a foundation.

\subsubsection{The Dual IIT System}

The dual IIT system is a morphologic evolution from the classified consolidated system, it clearly divide the income into capital gains and working income. And it applies single proportional tax to the capital income while apply progressive tax rate to the working gains.

The benefit of the dual model is that it could not only fairly adjust the income by using the progressive rate on working incomes, but promote the efficiency and lower the incentive for tax evasion in taxation by using the proportional income tax on capital gains.

However, the drawback of the dual system is that it could widen the income gap since the capital income which always acquired by the wealthy citizens are taxed in proportion without the progressive feature.

\subsubsection{The Unitary IIT Model}

The unitary tax model is the system that levies different IIT by using the same tax rate. It's more efficient in promoting the horizontal justice and the simplification of taxation. Nevertheless, since it applies the proportional rate system, the unitary model thus lacks the function in achieving the justice of taxation.

\subsubsection{The Application of the Classified Consolidated System}

In China , the current taxation system not only need to assume the function of maintaining fiscal revenue, but also have to further be used to adjust the gap of personal income and achieve the justice redistribution.

Nowadays, accompanied with the speedy development of national economy, the social contradictions and the 
personal income gap are more and more prominent in China. However, due to the inherent drawbacks of the classified system, the current Chinese tax system cannot adapt the function of adjusting the income gap and assuring the fairness distribution of wealth. Therefore, we can argue that the government should abandon the current classified taxation system while applying the classified consolidated system, the reason are as follows.

It is possible in reality that the global system is the most efficient model in effectively narrowing the income gap, however, the implementation of such mechanism need an effective tax declaration and information system as a foundation. And it requires the tax payers to completely record the household revenue and expenditure as well as demanding the tax organs to solve the storage, consolidation, analysis and collection problems by using developed levy methods. Since China do not have this qualification yet, the tax organs could not have a comprehensive understanding of the taxpayer's real income level, so it is more suitable for China to take the classification-consolidated system as a target for the current reform.

\subsection{Perfect the Marginal Tax Rate System.}

The elements that influence the progressive of the tax system include marginal taxation standard, number of tax stages and the span among tax rates. The most critical element is the marginal tax rate system, which includes the original tax rate and the ultimate marginal tax rate.

In the aspect of the original tax rate, take most OECD countries and developing countries as an example, the average initial tax rate of OECD countries are $14.65 \%$. However, the initial tax rate of developing countries and burgeoning countries are largely lower than the OECD countries. The expense deduction in current Chinese IIT system is 3500 yuan, the income of RMB 1500 or less after the deduction of RMB 3500 for expenses and an additional deduction for expenses from the monthly income need to pay $3 \%$ as its IIT, while the tax rate for the part of income in excess of RMB 1500 to 4500 is $10 \%$. However, the first and second level IIT tax rate are still comparatively high than the circumjacent countries. And the 3500 yuan deduction could not meet the basic needs of life for working class to some extent. Thus, the amendment of the IIT law should improve the deduction as well as expanding the scope of application for the initial $3 \%$ tax rate.

As to the highest marginal taxation rate, the current $45 \%$ supreme IIT tax rate is arguably too high. The exorbitant supreme IIT tax rate would not only affect China's competitiveness among international taxation, but stimulate the tax evasion and avoidance as there are many defects in the current IIT legislations. Therefore, due to the rare use of the supreme marginal tax rate, it is more suitable to lower the $45 \%$ supreme tax rate and expand the application scope of the supreme tax rate in order to both maintain the domestic competitiveness of international tax as well as increasing the IIT burden for wealthy people in order to minor the income gap.

\subsection{Reform of the Deduction System}

In the aspect of deduction, the current IIT deduction system is too simple, which executes fixed amount or proportion of deduction to all the tax payers while ignoring the ability-to-pay principal of taxation. This type of deduction might lead to inequity in tax burden among tax payers. In order to design a more reasonable deduction system, the following aspects should be taken into concern. Firstly, the basic living expense should be taken into concern by using diversified standard which in consideration of the life burden of different tax payers. More specifically, due to the basic national conditions and cultural elements, tax payers in China always have strong family values, accordingly, its revenue often need to bear the burden of expense for the whole family. More often than not, the income of domestic tax payers need to support the elderly, children, medical, housing and other basic living expenses in the whole family. It is more reasonable to set the deduction quantity in consideration of the specific living condition and due burden of tax payers, which would better embody the essence of the fair, as well as achieving the fairness in wealth redistribution.

Apart from that, in order to prevent the ungears between the real living expense and deduction caused by the inflation and deflation in the market, China could consider to reference the national tax indexation system applied by many western countries, which connect the deduction with the real modification of CPI and give adjustment to the amount of the annual deduction.

Thirdly, the amendment of the IIT law could also consider implementing differentiated expense deduction in different regions. As a result of the wide spatial distributions, there are still outstanding development gap among provinces and regions, which largely lead to the differentia of living cost among the residents of different regions.

Under these circumstances, the current unified deduction system would actually generate inequality among tax payers with different living areas, revenue and living burden. Therefore, in order to promote the substantive fairness of tax payers, the amendment of the IIT system could design a differential deduction system according 
to the specific development level, economic status and the price level of different regions.

\subsection{Expand the Scope of Domestic Individual Income Taxation}

In order to promote the redistribution ability of the Chinese IIT and realize the fairness redistribution of personal income, the IIT system needs to ensure the scale of its taxation. However, the current IIT scale is still too small, which cannot efficiently achieve its objection of wealth redistribution. Thus, the tax base of IIT need to be expanded in order to include more types of new income channels into the IIT system. In the aspect of the legislative technique ,the legislator are supposed to use the inverted listing to substitute for the current positive listing and expand the scope of taxable items in order to increase the volume and range of the taxable items.

\subsection{Reform of the Correlative Tax Levy System}

\subsubsection{Cut down the Use of Cash in Taxable IIT Income Payment}

In order to avoid the evading of IIT, the cash payment of salary should be restricted, which has a comparatively high flow ability as well as difficulty in monitoring. In order to promote the wealth redistribution function of the IIT, the amended IIT law system should promote the use of banking transfer system in order to better monitor the information of the real revenue and reduce the unfair redistribution caused by the evading of taxation.

\subsubsection{The Establishment of Personal Credit Constraint Mechanism}

The current widespread smuggling of taxes in domestic China refracts the low cost of breaking the law. In western countries, one of the key the reasons for the rare tax evasion is the strict monitor of personal reputation mechanism, which largely improve the cost of breaking the law. In order to better realize the wealth redistribution function of the IIT and promote the tax payers to voluntarily pay the tax, China are proposed to build a credit system for the whole society by referencing the western experience and imitating the relatively mature domestic credit reference system.

\subsubsection{Perfect the Voluntary Declare System and Establish the Tax Payer's Coding System}

One of the key elements that cause the weak adjustment of the IIT mechanism in wealth redistribution is the imperfection of the levy system which leads to the widespread of tax evasion. And the lack of national unified tax payers' identification number system and taxation information system seriously lead to the defects in the levy of IIT. It is of great difficulty for the tax organs to accumulate and supervise the personal income information without such mechanisms. Therefore, the government should start to set up both the national network individual tax coding information system and the declaration system matched with the withholding at source mechanism in order to avoid the individual tax evasion.

More specifically, in order to build the declaration system, the government could consider to connecting the relevant bank account with the current individual secondary ID card, which could efficiently include the declaration and information of tax payers as well as getting more comprehensive tax information from taxpayers. And this mechanism would finally prevent the tax evasion and guarantee the well implementation of the IIT system.

Apart from that, due to the limitation of the supervision resources, an efficient individual declaration system should also be built. What's more, in order to urge taxpayers to consciously declare their real taxable income. The declaration system should cooperate with the tax payers' identification number system, taxation information system and the credit system.

\section{Conclusion}

China enjoys rapid economic development after its "open the door" policy since 1990s, but it has been accompanied by a widening income gap between the rich and the poor. As an acknowledged useful tool in distribution adjustment, it is undeniable that the current Chinese IIT legal system faces many problems and challenges. Without deep reforming, it might lead to a broaden wealth gap in China rather than achieving its original goal of narrowing the gap between different stratum. The current defects of the IIT system come from many different aspects showed in the preceding discussions. Therefore, In order to better achieving the wealth redistribution function of the IIT, the current Chinese IIT system need to be reformed in the aforementioned aspects. And the reform of the current Chinese IIT system would give contribution to the achievement of a more reasonable and more even wealth redistribution structure; however, in order to finally reach the ideal structure, the IIT system still needs the cooperation of other policies and facilities.

\section{References}

Feng, X. M., \& Wang, W. L. (2012). Qianxi Gerensuodeshui Dui Shourufenpei De Tiaojie Zuoyong. Tax Forum, 
7.

Liu, J. W. (2007). Financial and tax law. Law Press China.

Liu, L. (2011). Woguo Gerensuodeshui Leijin shuilvjiegou Sheji Tantao. Taxation Research, 3. Retrieved from http://www.cnki.net/KCMS/detail/detail.aspx?QueryID $=4 \&$ CurRec $=7 \&$ recid $=\&$ filename $=$ SWXH20110301 $1 \&$ dbname $=$ CJFD2011\&dbcode $=$ CJFQ \&pr $=\& u r l i d=\& y x=\& v=$ MDY3Mjk5RE1ySTlFWliSOGVYMUx1eF ITN0RoMVQzcVRyV00xRnJDVVJMNmVadWR1RkNqa1VydkJOanJUWnJHNEg=

MOF: Chinese IIT accounts for $5.8 \%$ of the individuals' revenue. Retrieved from http://finance.sina.com.cn/china/20130211/084214547487.shtml

Notice of the state council on approving and forwarding opinions of NDRC MOF and MOHRSS on deepen the reform of the system for income distribution. Chinese government website. Retrieved from http://news.xinhuanet.com/politics/2013-02/05/c_114625507.htm

Postlewaite, P. F., \& Collins, M. P. (1982). International individual taxation. Colorado Springs, Colo.: Shepard's/McGraw-Hill.

Shi, Z. W. (2011). Fenpei Zhengyi Yu Gerensuodeshuifa Gaige. China Legal Science, 5. Retrieved from http://www.cnki.net/KCMS/detail/detail.aspx?QueryID=1\&CurRec=1\&recid=\&filename=ZGFX201105006 $\&$ dbname $=$ CJFD2011\&dbcode $=$ CJFQ \&pr $=\& u r l i d=\& y x=\& v=$ MzIzOTF1RkNuZ1dyM0JQeXJOZHJHNEg 5RE1xbzlGWW9SOGVYMUx1eFITN0RoMVQzcVRyV00xRnJDVVJMNmVadWQ=

Shi, Z. W. (2012). Woguo Nashuipingdin Zhidu de Falvgoujian. Chian Taxation, 9. Retrieved from http://www.cnki.net/KCMS/detail/detail.aspx?QueryID=11\&CurRec=19\&recid=\&filename=ZGSW201209 019\&dbname $=$ CJFD2012 \&dbcode $=$ CJFQ \&pr $=\& u r l i d=\& y x=\& u i d=$ WEEvREcwSIJHSldTTGJhYkdqaVE3 RINQTFIMd2o4Z1BaZHFENjU4Z0t6KzMzR2VJelZScE1DUThleldBR20ybm5Ucz0=\$9A4hF_YAuvQ5o bgVAqNKPCYcEjKensW4IQMovwHtwkF4VYPoHbKxJw!!\&v=MDAxNDBIWDFMdXhZUzdEaDFUM3 FUcldNMUZyQ1VSTDZ1WnVkdUZDcmtVcnZLUHlyWWViRzRIOVBNcG85RWJZUjg=

Sun, G. (2011). Shixi Shuishou Dui Woguo Shouru Fenpei De Tiaojie. Tax Research, 3.

Wang, X. L. (2010). Woguo Shourufenpei Xianzhuang Qushi Ji Gaigesikao. Chian Market, 20. Retrieved from http://www.cnki.net/KCMS/detail/detail.aspx?QueryID=15\&CurRec=1\&recid=\&filename=SCZG20102000 $5 \&$ dbname $=$ CJFD2010\&dbcode $=$ CJFQ \&pr $=\& u r l i d=\& y x=\& v=$ MDQ2NjRSTDZIWnVkdUZDbmhVYnpM Tmk3UmFiRzRIOUhPcjQ5R1lZUjhlWDFMdXhZUzdEaDFUM3FUcldNMUZyQ1U=

Zee, H. H. (2005). Personal Income Tax Reform: Concepts, Issues, and Comparative Country Practices. IMF working paper WP/05/87. Washington,DC: International Monetary Fund.

Zee, H. H., \& Hameed, F. (2006, March-April). Reforming China's Personal Income Tax. The Chinese Economy, 39(2), 40-56. http://dx.doi.org/10.2753/CES1097-1475390204

Zhang, S. W. (2012). Theories of taxation law. Peking University Press.

\section{Copyrights}

Copyright for this article is retained by the author(s), with first publication rights granted to the journal.

This is an open-access article distributed under the terms and conditions of the Creative Commons Attribution license (http://creativecommons.org/licenses/by/3.0/). 